\title{
Choosing the right treatment for patients with psoriatic arthritis
}

\author{
Maria Noviani, Marie Feletar, Peter Nash and Ying Ying Leung ${ }^{(D)}$
}

\begin{abstract}
Psoriatic arthritis (PsA) is a chronic inflammatory condition with articular and extra-articular manifestations: peripheral arthritis, axial disease, enthesitis, dactylitis, psoriasis, inflammatory bowel disease and uveitis. Anti-tumour necrosis factors (anti-TNFs) have demonstrated clinical efficacies exceeding those of conventional disease-modifying antirheumatic drugs (DMARDs). New understanding in pathogenic pathways have led to novel therapeutic targets. The current treatment paradigms emphasize early diagnosis and treatment, and treating towards remission and low disease activity status, particularly in longstanding disease. This review addresses the evidence of current treatment options for each of the domains of PsA. We present a simple guide that weighs on clinical efficacies for each PsA domain to aid clinicians in choosing the most appropriate treatment for patients. We highlight the unmet need for biomarkers of treatment response, and future perspectives with precision medicine in PsA.
\end{abstract}

Keywords: manifestations, psoriatic arthritis, review, therapies

Received: 6 July 2020; revised manuscript accepted: 2 September 2020.

\section{Introduction}

Psoriatic arthritis (PsA) is distinct from other inflammatory arthritis in terms of pathogenesis, clinical manifestations and response to treatment. ${ }^{1}$ The manifestations of PsA are diverse involving peripheral joints, entheses, dactylitis and axial skeleton. ${ }^{1,2}$ In some patients, manifestations extend beyond bone and joint to inflammatory bowel disease (IBD) and uveitis. Further, there is an increased prevalence of metabolic syndrome and cardiovascular disease among patients with PsA. ${ }^{3}$ Over time, PsA leads to joint destruction, deformities, disability, impaired quality of life and even reduced life expectancy. $2,4,5$

Advances in treatment options have revolutionized management of PsA in the past two decades. Early diagnosis and treating to remission or low disease activity target, the treat-to-target approach (T2T), are now the current standard strategy of treatment. ${ }^{6}$ Targeting towards a minimal disease activity (MDA) state with disease modifying antirheumatic drugs (DMARDs) has been shown to be feasible in clinical practice. ${ }^{7}$ Evidence suggests that patients achieving MDA tend to have less joint damage, ${ }^{8}$ improved quality of life and work productivity, ${ }^{9}$ and reduced atherosclerosis and arterial stiffness over time. ${ }^{10}$

The Group for Research and Assessment of Psoriasis and Psoriatic Arthritis (GRAPPA) and the European League against Rheumatic Diseases (EULAR) have published recommendations for the management of PsA with pharmacological therapies. ${ }^{11,12}$ The GRAPPA has suggested treatment based on the manifestations (domains): peripheral arthritis, skin and nail involvement, enthesitis, dactylitis and axial arthritis, ${ }^{12}$ which would remain as the general approach in the upcoming recommendation. Traditionally, EULAR used an algorithmic approach that focused mainly on peripheral arthritis, ${ }^{13}$ and in the recent updated recommendation, more considerations have been given to the other manifestations, namely polyarthritis, oligoarthritis, enthesitis, dactylitis and axial diseases. ${ }^{14}$

Despite the tremendous effort to promote T2T, $30-40 \%$ of patients do not achieve adequate response to therapies. Currently there is no
Ther Adv Musculoskel Dis 2020, Vol. 12: 1-17

DOI: 10.1177/ $1759720 \times 20962623$

(c) The Author(s), 2020. Article reuse guidelines: sagepub.com/journalspermissions
Correspondence to: Ying Ying Leung Department of Rheumatology and Immunology, Singapore General Hospital, level

4, Academia, 20 College Road, Outram Road, Singapore 169608,

Singapore

Duke-NUS Medical School, Singapore katyccclahotmail.com

Maria Noviani

Department of Rheumatology and Immunology, Singapore General Hospital, Singapore

Duke-NUS Medical School, Singapore

Marie Feletar Rheumatologist, Melbourne, Victoria, Australia

Peter Nash

School of Medicine, Griffith University, Brisbane, Queensland, Australia 
biomarker that could predict treatment response, and individual therapies are chosen based on efficacy and safety data derived from clinical trials. Since our last review on this topic, ${ }^{15}$ it is timely to update the treatment options for PsA, in particular, giving insights into choosing the appropriate treatment for PsA patients.

\section{Pathogenesis and therapeutic targets}

Cytokines have been identified as pivotal in chronic inflammatory diseases, this concept has been supported by the homogeneity of therapeutic response to inhibition of tumor necrosis factor-alpha (TNF$\alpha$ ) in rheumatoid arthritis (RA), as well as spondyloarthropathies and related illnesses including psoriasis ( $\mathrm{PsO}$ ), PsA, ankylosing spondylitis (AS) and IBD. For many years, PsA was thought to be a $\mathrm{T}$ helper (Th) 1-mediated disease, with large amounts of interferon- $\gamma$ and interleukin (IL)-12 production. ${ }^{16}$ New focus has been in the Th-17 cells and the related cytokines, IL-17 and IL-23, which modify the innate immunity and play major roles in the immunopathogenesis of PsA, spondyloarthritis (SpA) and IBD. ${ }^{17}$ A lineage of resident $\mathrm{T}$-cells bearing the ROR $\gamma \mathrm{t}$ receptors in the enthesis has been identified and, upon stimulation with IL-23, leads to development of entheseal inflammation and local bone erosion and proliferation through IL-17 and IL-22. ${ }^{18}$ Entheseal inflammation was suggested as the origin of PsA and inflammation subsequently spread to the synovium, ${ }^{19}$ although this notion is still controversial. ${ }^{17,20}$

While preclinical studies support the central role of IL-23/IL-17 axis in models of SpA and IBD, clinical trials seem to show a divergent response to IL-23/IL-17 inhibition among these disease entities. ${ }^{21}$ For instance, ustekinumab, the extensively trialled agent inhibiting cytokines IL-23 and IL-12 (via neutralization of their shared $\mathrm{p} 40$ component), has substantial clinical efficacy in $\mathrm{PsO}$ but less so for PsA. Further, both ustekinumab and risankizumab (monoclonal antibody against p19 protein of IL-23) failed to show clinical efficacies in AS in phase III RCTs. ${ }^{22,23}$ In Crohn's disease IL-12 and IL-23 inhibition had clinical efficacies only in some patients, and IL-17 inhibition may aggravate the symptoms of Crohn's disease. ${ }^{24}$ The clinical efficacies of IL-17 inhibition seem to be similar between PsA and AS, albeit a higher dose of drug may be required for PsA. ${ }^{25,26}$

The discrepancy in efficacy between IL-17 inhibition and IL-23 inhibition in diseases such as
Crohn's disease and AS might be explained by uncoupling of IL-17 and IL-23, attributed to the unique immunopathological microenvironment. Pre-clinical studies suggest differential contribution of IL-23 to the local production of IL-17 at different anatomical sites. ${ }^{27}$ In addition, some cell types can produce IL-17 independently of IL-23. One example is type 3 innate lymphoid cells (ILC3s), ${ }^{28}$ which are important for homeostasis and repair in barrier tissues such as skin, ${ }^{29}$ and have been found in human enthesis and may play role in the pathogenesis of spondyloarthropathies. ${ }^{30}$

\section{Therapeutic options}

Methotrexate and other conventional disease modifying anti-rheumatic drugs (cDMARDs)

Methotrexate (MTX) is often given as first-line treatment for peripheral arthritis of PsA by most rheumatologists despite a paucity of clinical trials and commercial interest examining its utility in this disease. The largest randomised controlled trial (RCT) to ask this question was the MIPA (Methotrexate in Psoriatic Arthritis) study, in which 221 patients with active PsA were randomized to MTX or placebo for 6 months. ${ }^{31}$ Notably the MTX dose was capped at $15 \mathrm{mg} /$ week, and patients tended to have milder disease than seen in the biologic trials of the same era. Nevertheless, results showed that compared with the placebo arm, MTX treated patients had significant improvements only in physician global assessments and mean Psoriasis Area and Severity Index (PASI) score, but no significant difference in efficacies in tender and swollen joint counts, pain, physical function and inflammatory markers. Drawing largely from the aforementioned trial, a Cochrane systematic review concluded that oral MTX (15 mg weekly or less) taken for 6 months was found to be only slightly more effective than placebo in treating PsA. ${ }^{32}$

However, data derived from the tight control of psoriatic arthritis (TICOPA) trial showed that patients taking MTX alone experienced improvement in peripheral joint disease, skin disease, enthesitis, dactylitis and nail disease during the 12 -week treatment. In total, $22.4 \%$ of patients achieved MDA at 12 weeks on MTX alone. ${ }^{7}$ In a recent large RCT that compared MTX monotherapy with etanercept or the combination, $31 \%$ and $51 \%$ of the 284 PsA patients randomized to MTX monotherapy achieved the 
American College of Rheumatology (ACR)20 and ACR50 responses, although the efficacy of MTX was lower than that of etanercept or the combination. ${ }^{33}$ In another smaller RCT in patients with newly diagnosed PsA, comparing MTX with MTX and golimumab combination, $42 \%$ and $29 \%$ of patients randomized to MTX achieved DAS remission and MDA at week $22 .{ }^{34}$ Even without a placebo arm, MTX in these trials has demonstrated capacity in reducing signs and symptoms in a sizable proportion of patients with active PsA. Thus, the clinical utility of MTX is recognized, and it continues to have a role as a relatively low risk therapy used by clinicians worldwide, and to be included in guidelines for PsA. ${ }^{35}$

The efficacies of other cDMARDs, including sulfasalazine and leflunomide, have been summarised previously. ${ }^{15}$ Overall, there is weak evidence of their use in treatment of peripheral arthritis in PsA. Currently no data exists for efficacies of cDMARDs in dactylitis and enthesitis or retardation of radiological progression. Sulfasalazine was not efficacious in relieving back pain in AS, ${ }^{36}$ and no data exists for efficacies of cDMARDs in axial PsA. MTX and other cDMARDs are recommended both by GRAPPA and EULAR as the initial choice of treatment for active peripheral arthritis in PsA, while GRAPPA has recommended to consider an early escalation of therapy for patients with poor prognostic factors, such as high inflammatory markers and high active joint counts. ${ }^{12}$

\section{Anti-TNFs}

In the past two decades, five anti-TNFs, including infliximab, etanercept, adalimumab, golimumab and certolizumab pegol, have been approved for the treatment of PsA by the United States (US) Food and Drug Administration (FDA). Anti-TNFs are superior to cDMARDs in improving arthritis, enthesitis, dactylitis, skin and nails. Further, anti-TNFs are also more efficacious in preventing joint destruction and radiographic progression than cDMARDs. $33,34,37-42$ Between the different anti-TNFs, there seems to be no significant differences in efficacies and safety. Across different RCTs, the proportions of patients achieving ACR20, ACR50 and ACR70 were approximately $60 \%, 40 \%$ and $20 \%$, respectively in the anti-TNF arms at 24 weeks (commonly the time of primary endpoint). We summarised the clinical efficacies of anti-TNFs treatment arms of these trials at week 24 in Table 1. Of note, these comparisons were not based on head-to-head comparison in the same RCT, and could only give a general impression on clinical efficacies of these anti-TNFs. These RCTs recruited mainly patients with polyarthritis and peripheral joint disease. Yet, in the subgroups of patients who had dactylitis and enthesitis at baseline, statistically significant differences in dactylitis and enthesitis score clearance were observed in patients receiving anti-TNFs compared with placebo. Etanercept showed numerically lower clinical efficacies in peripheral joints, dactylitis, enthesitis, and PsO. ${ }^{38}$ The PRESTA trial compared two doses of etanercept, and found that etanercept given at $50 \mathrm{mg}$ twice weekly had superior skin response compared with standard dose given at $50 \mathrm{mg}$ once weekly (physician's rate clearance $46 \%$ versus $32 \%, p<0.001$ ), but there was no significant difference in efficacies in peripheral arthritis, dactylitis and enthesitis. ${ }^{43}$ In general, all anti-TNFs showed moderate clinical efficacies in $\mathrm{PsO}$.

Out of these RCTs, patients receiving intravenous golimumab evaluated in the GO-VIBRANT trial achieved numerically higher ACR20, 50 and 70 responses of $78 \%, 54 \%$ and $33 \%$ than the expected benchmark. ${ }^{41}$ This trial allowed the adjustment of dose of golimumab according to body weight at $2 \mathrm{mg} / \mathrm{kg}$ every 8 weeks after loading doses at week 0 and week 4 . Anti-TNF pharmacokinetics could be affected by body weight. ${ }^{48}$ Obesity has been shown to be associated with a decreased response to anti-TNFs, and this may be secondary to changes in volume distribution or insufficient dosing. ${ }^{48,49}$ However, in the GO-REVEAL trial comparing $100 \mathrm{mg}$ and $50 \mathrm{mg}$ of golimumab in PsA, there were only modest differences in ACR responses between $100 \mathrm{mg}$ and $50 \mathrm{mg}$ of golimumab given subcutaneously (ACR20 61\% versus $52 \%$ at week 24). ${ }^{40} \mathrm{PsA}$ patients had higher prevalence of metabolic syndrome and obesity, ${ }^{50}$ and a higher dose of antiTNF or dose adjustment may be necessary in obese patients.

The combination of MTX with anti-TNFs were shown to be superior than anti-TNFs alone in RA. ${ }^{51,52}$ No difference in efficacies was noted in most RCTs in PsA patients taking anti-TNFs with or without MTX. ${ }^{53}$ The SEAM-PsA trial used a similar study design as TEMPO in RA to evaluate the efficacy of MTX alone, etanercept alone or their combination in 851 patients with active PsA. ${ }^{33,52}$ Contrary to the results found in TEMPO in RA, the combination of MTX and 


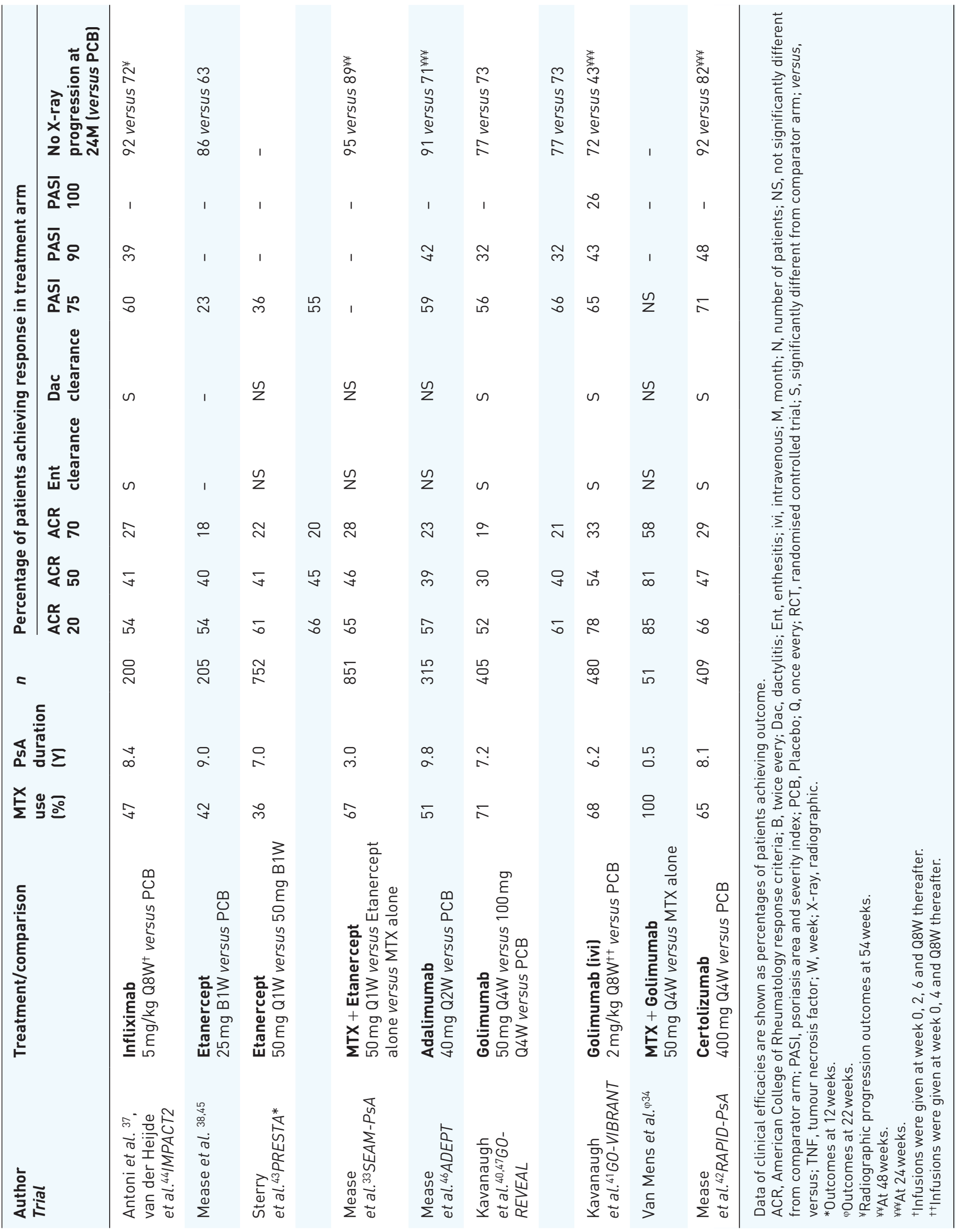


etanercept was not superior to etanercept alone, and etanercept in PsA was more efficacious than MTX monotherapy in achieving ACR responses and reducing radiographic progression. ${ }^{33}$

Previous RCTs with anti-TNFs in PsA have recruited patients with long disease duration. Data from observational studies show that delayed diagnosis and treatment lead to poorer outcomes in PsA. ${ }^{54}$ More recently, investigators are interested to find out whether treating patients earlier may improve efficacies. In a small investigatorinitiated RCT, Van Mens et al. recruited PsA patients with mean duration of illness of 0.5 years and randomised the patients to either golimumab plus MTX or MTX alone. ${ }^{34}$ DAS remission rate was almost double at week 22 in the golimumab/ MTX combination arm as compared with MTX alone. These findings provide proof of concept for the potential role of early intervention with anti-TNF monotherapy in PsA to achieve remission. The GOLMePsA study is an ongoing investigator-initiated trial evaluating Golimumab and MTX, compared with MTX alone, for 52 weeks in very early PsA using clinical and whole-body magnetic resonance imaging outcomes in a centre in the United Kingdom (UK). ${ }^{55}$ Recruitment was started in 2015, the results will shed more lights on whether very early treatment with anti-TNF may lead to better clinical and radiographical outcomes in PsA than conventional therapy.

In short, anti-TNFs have very good efficacies in treatment of peripheral arthritis in PsA, and moderate efficacies in treatment of dactylitis and enthesitis. Treatment of axial domain of PsA have been borrowed from evidence in AS and axial SpA, for which anti-TNFs have demonstrated good efficacies in treatment of back symptoms. ${ }^{56}$ Efficacies for $\mathrm{PsO}$ have been moderate. ${ }^{57}$ For extra-articular manifestations, monoclonal antibodies of anti-TNFs, adalimumab, infliximab, and certolizumab are approved treatments for IBD. The use of infliximab and adalimumab for uveitis have been well described. ${ }^{58}$

\section{IL-17 inhibitors}

Several IL-17 inhibitors have been approved for the treatment of PsA (Table 2). Secukinumab is a fully humanized monoclonal antibody that selectively binds to IL-17A. Based on FUTURE-1 and FUTURE-2 trial, secukinumab has been shown to be efficacious for patients who are anti$\mathrm{TNF}$ naïve and for those with inadequate response to anti-TNFs (TNFi-IR). ${ }^{59,60}$ Both $150 \mathrm{mg}$ and $300 \mathrm{mg}$ of secukinumab provided significant improvements in peripheral joints as compared with placebo, although secukinumab efficacy in peripheral joint appears modest compared with anti-TNFs particularly for the $75 \mathrm{mg}$ regimen. . $^{59,60}$ Clearance of enthesitis and dactylitis were reported in one-third to one-half of patients who received secukinumab. Remarkable response in $\mathrm{PsO}$ was reported, and over $40 \%$ of patients who received $150 \mathrm{mg}$ and $300 \mathrm{mg}$ of secukinumab reported PASI90 response. ${ }^{57}$ In line with these findings, FUTURE-3 trial demonstrated good efficacies across multiple domains with secukinumab administered subcutaneously, and higher ACR20 response was achieved with $300 \mathrm{mg}$ of secukinumab compared with $150 \mathrm{mg}$ regimen ( $41 \%$ versus $34 \%$ ) in the TNFi-IR subgroup. ${ }^{61}$ In the FUTURE-4 study, patients who received the loading dose regimen had better clinical response and achieved it earlier than those who received regimen without loading dose. ${ }^{62}$ FUTURE-5 study showed that both $150 \mathrm{mg}$ and $300 \mathrm{mg}$ of secukinumab, administered with and without loading dose, inhibited radiographic progression at week 24, as compared with placebo. ${ }^{63}$ In a pooled analysis of RCTs involving over 7000 patients with PsO, PsA and AS, secukinumab was found to be safe and tolerable over 5 years. ${ }^{64}$

Ixekizumab is a recombinant monoclonal antibody against IL-17A. Data from SPIRIT-P1 trial shows that ixekizumab is efficacious to treat patients with PsA who had inadequate response to CDMARD and were biologic naïve. ${ }^{66}$ Comparable ACR responses, clearance of enthesitis and clearance of dactylitis were reported for ixekizumab and adalimumab. Numerically better efficacies in $\mathrm{PsO}$ were seen for ixekizumab than adalimumab, with clearance of plaque $\mathrm{PsO}$ achieved in $43-53 \%$ of ixekizumab-treated patients compared with $24 \%$ of adalimumab treated patients. In SPIRIT-P2, ixekizumab was also found to be efficacious in patients who were TNFi-IR. ${ }^{67}$ Overall, ixekizumab had excellent efficacies in $\mathrm{PsO}$ and comparable efficacies in peripheral arthritis, dactylitis and enthesitis as anti-TNFs.

Data from SPIRIT and FUTURE trials highlight the role of IL-17 in the pathogenesis of PsA and the use of IL-17 inhibitor as an alternative treatment to anti-TNFs in patients with active peripheral PsA. Excellent response in $\mathrm{PsO}$ is relevant to patients who have severe skin disease. Both 


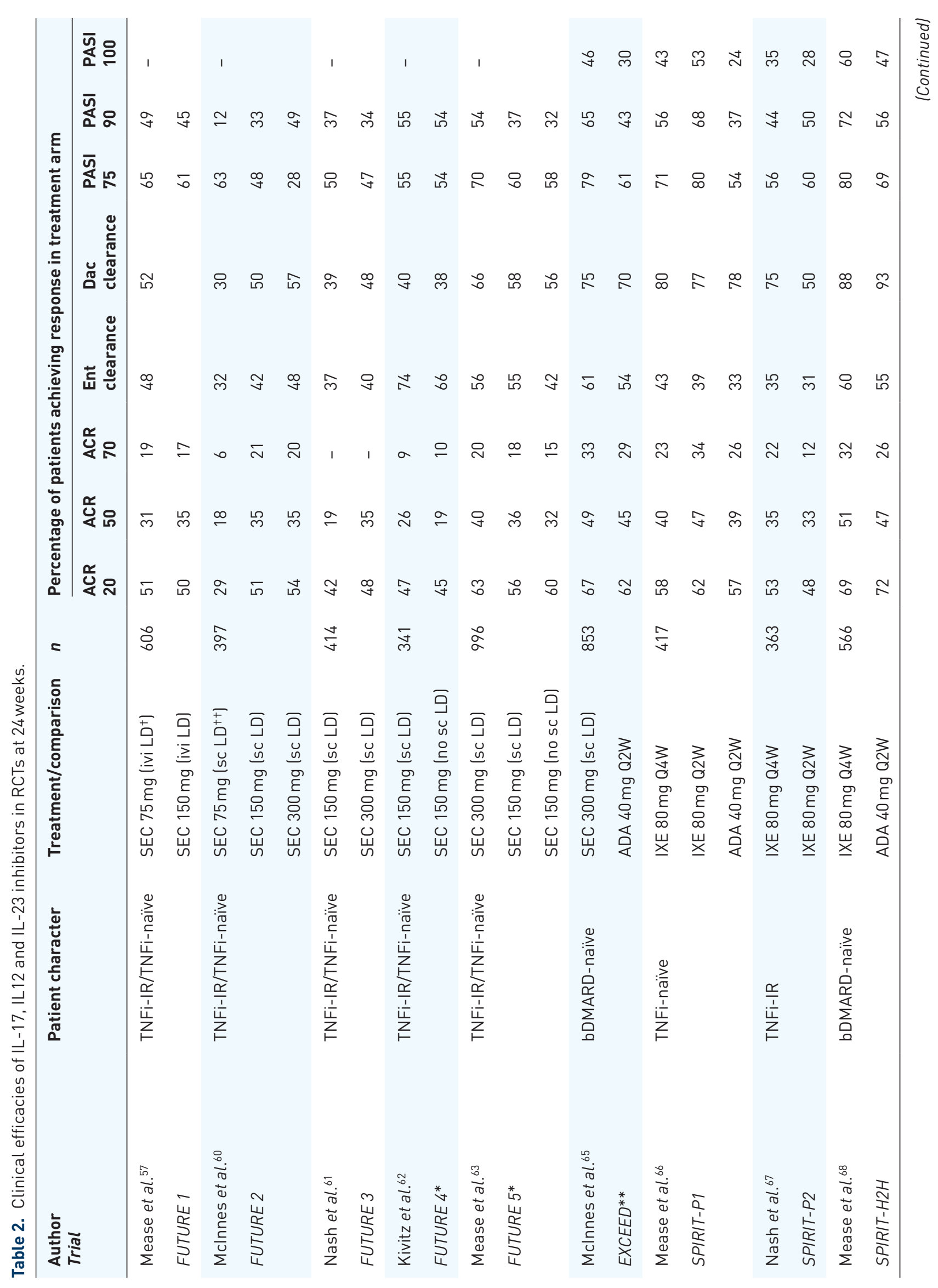




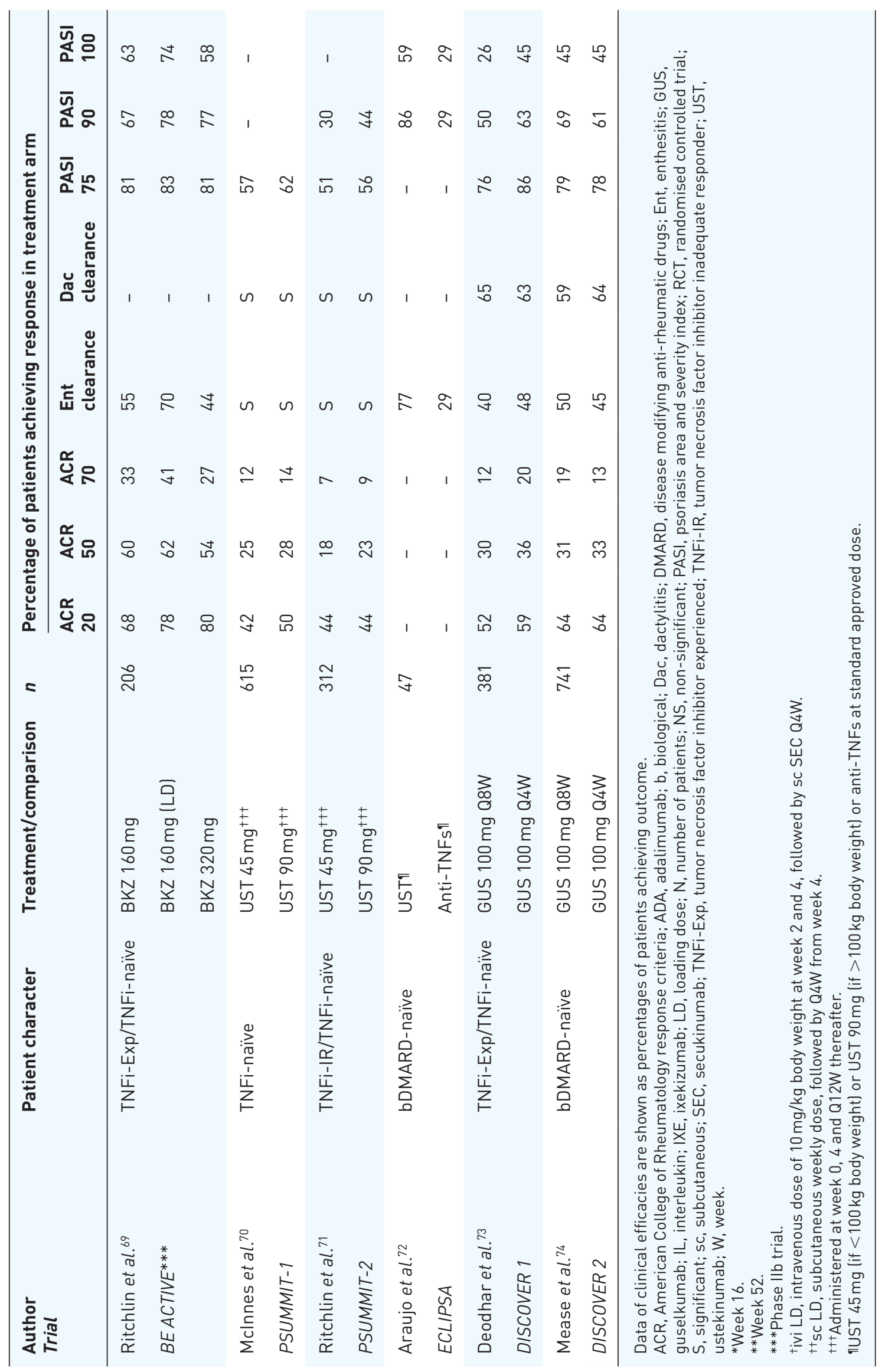


secukinumab and ixekizumab show clinical efficacies in relieving back symptoms compared with placebo, and are FDA-approved treatments for AS and axial SpA. ${ }^{56,75}$

Inhibition of IL-17 seems to be efficacious for uveitis at doses much higher than standard rheumatological doses, but has not been of therapeutic value for IBD. The efficacy of secukinumab given in high dose $(10 \mathrm{mg} / \mathrm{kg})$ intravenously was demonstrated in an open-labelled proof of concept study for chronic non-infectious uveitis in patients with RA, PsA and PsO. ${ }^{76}$ The result was supported by a subsequent small RCT reporting a high response rate of $78 \%$ with high intravenous dose of secukinumab in non-infectious uveitis. ${ }^{77}$ However, secukinumab failed to show therapeutic effect in Crohn's disease, and it led to higher rates of adverse events including infection. ${ }^{24}$ Nevertheless, IL-17 inhibition per se does not seem to increase the risk of IBD. Pooled safety data for secukinumab from 21 clinical trials, involving $7355 \mathrm{PsO}, \mathrm{PsA}$ and AS patients with cumulative exposure of 16,227 patient-years, show that the incidence of IBD were extremely rare with exposure adjusted incidence rates ranges (EAIR) of 0.01 to $0.13 .{ }^{78}$ The EAIR of IBD did not increase over time. ${ }^{78}$ Similarly, ixekizumab use in PsA and $\mathrm{PsO}$ trials was not associated with higher incidence of IBD. ${ }^{79,80}$ The role of IL-17 expression in normal and inflamed bowel mucosa is under further investigation.

For patients with high risk of tuberculosis reaction, or patients living in regions with high prevalence of tuberculosis, IL-17 inhibitors may be preferred over anti-TNFs. No case of tuberculosis has been observed from several RCTs of IL-17 inhibition. ${ }^{81,82}$ This included data from five RCTs of secukinumab for $\mathrm{PsO}$, with a total of 2044 patients, including 132 with history of treated pulmonary tuberculosis. ${ }^{82}$ Another pooled data from 10 RCTs of secukinumab for PsO involved 3993 patients, again, did not report any case of tuberculosis. ${ }^{83}$ Consistent with findings from clinical trials, in vitro study using human microgranuloma model showed no mycobacterial reactivation after secukinumab treatment, suggesting low risk of mycobacterial infection, in contrast to anti-TNFs treatment. ${ }^{82}$

Recent head-to-head trials comparing IL-17 inhibitor with anti-TNFs in patients with active PsA and inadequate response to cDMARD further supported the role of IL-17 inhibition to improve both musculoskeletal and skin manifestations in those naive to bDMARD. In the EXCEED trial $(n=853)$ comparing secukinumab with adalimumab, although secukinumab did not meet statistical significance for superiority, secukinumab resulted in numerically higher clinical responses across skin and musculoskeletal endpoints with ACR20 response achieved in $67 \%$ and $62 \%$ of patients in the secukinumab and adalimumab groups, respectively, at week 52 (OR 1.30, 95\% CI $0.98-1.72 ; p=0.0719) .{ }^{65}$ Although the superiority of secukinumab to adalimumab in $\mathrm{PsO}$ was not statistically powered, the PASI responses were significantly higher in the secukinumab than adalimumab arm (PASI100 46\% versus 30\%, $p=0.0007)$. The superiority of ixekizumab compared with adalimumab has been demonstrated in the SPIRIT-H2H trial $(n=566)$, using a composite ACR50 and PASI100 endpoint at week 24 ( $36 \%$ versus $28 \% ; p=0.036$ ). ${ }^{68}$ This superiority was driven mainly by the superior $\mathrm{PsO}$ response of ixekizumab compared with adalimumab (PASI100 $60 \%$ versus $47 \%, p=0.001) .{ }^{68}$ ACR 50 response in ixekizumab was not statistically different and noninferior compared with adalimumab at week 24 $(51 \%$ versus $47 \%) .{ }^{68}$

Up to $30-50 \%$ of patients, however, have persistent arthritis or arthritis flare despite IL-17A inhibitors. New therapy targeting the IL-17 family has been studied. BE ACTIVE trial is a phase IIb dose RCT ( $n=206)$ investigating the efficacy and safety of bimekizumab, a selective monoclonal antibody targeting both IL-17A and IL-17F receptors. ${ }^{69}$ The results suggested that bimekizumab is efficacious across all clinical domains in PsA without new safety concerns. ${ }^{69}$ Phase III trials are ongoing in PsA comparing bimekizumab with placebo [BE COMPLETE, ClinicalTrials. gov identifier: NCT03896581] and with placebo as well as adalimumab as comparators $[\mathrm{BE}$ OPTIMAL, ClinicalTrials.gov identifier: NCT03895203].

\section{IL-12 and IL-23 inhibitors}

IL-23 is a heterodimeric cytokine with p19 and p40 subunit, and the p40subunit is shared with IL-12. Ustekinumab is a monoclonal antibody directed against the p40 subunit of IL-12 and IL-23. The FDA approved ustekinumab use in PsA in 2013 based on two prior phase III trials: PSUMMIT-1 and PSUMMIT-2 (Table 2). ${ }^{70,84}$ Ustekinumab was shown to be efficacious in improving arthritis in those who were TNFi-naïve 

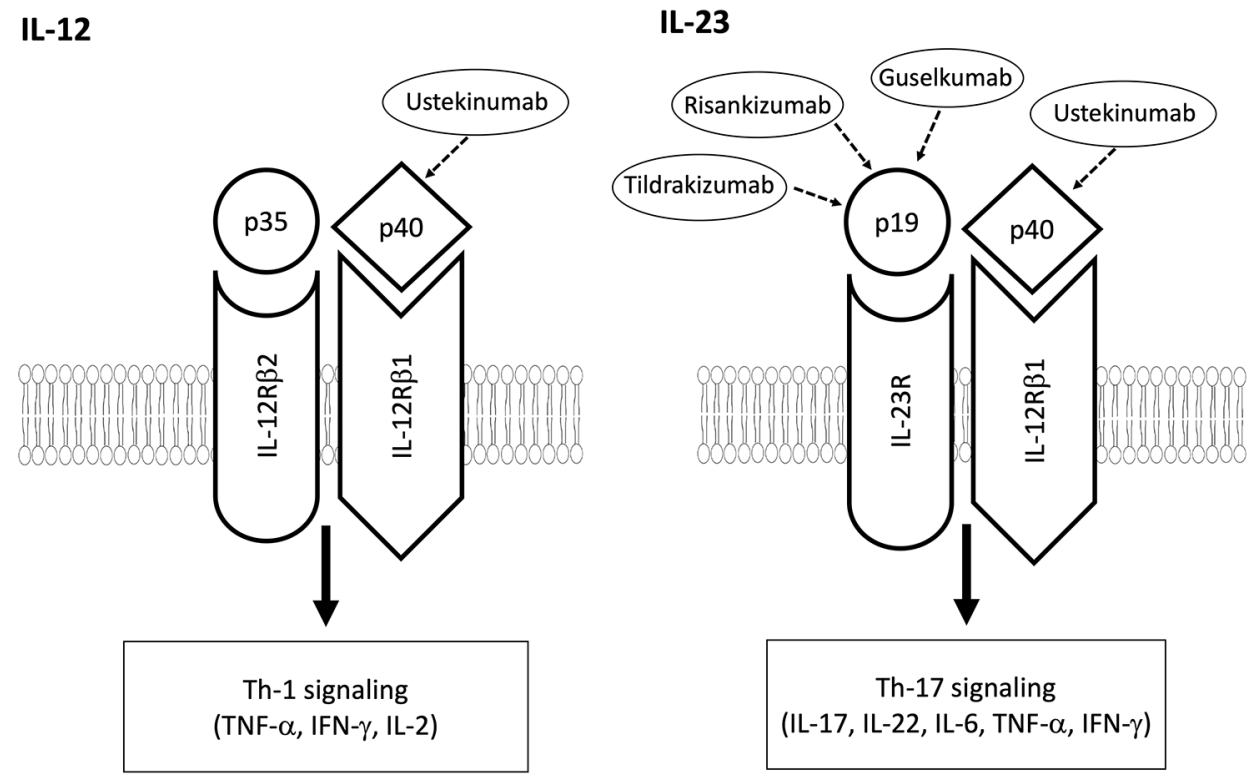

Figure 1. Differences between IL-12 and IL-23, which share a common p40 subunit. The blockage of p40 subunit inhibits both Th-1 signalling and Th-17 signalling, while blockage of p19 subunit inhibits the Th-17 signalling.

IFN, interferon; IL, interleukin; R, receptor; Th, T helper; TNF, tumor necrosis factor.

$\rightarrow$ inhibitory.

and TNFi-IR. In the PSUMMIT-1 trial, which included patients who were TNFi-naïve, $42 \%$ and $50 \%$ of patients who received $45 \mathrm{mg}$ and $90 \mathrm{mg}$ of ustekinumab achieved ACR20 response at week 24, respectively. ${ }^{70}$ In PSUMMIT-2, which included $58 \%$ of patients with prior experience with anti-TNFs $(>70 \%$ had inadequate response or intolerant), $44 \%$ of patients who received secukinumab achieved ACR20 response at week 24 , and a lower response rate was seen in patients who had prior experience with antiTNFs. ${ }^{71}$ Ustekinumab also inhibited radiographic joint damage and was shown to improve $\mathrm{PsO}$, dactylitis and enthesitis. ${ }^{70,71,85}$ As the IL-12/23 pathways are central to the pathogenesis of enthesitis, inhibition of this pathway should theoretically lead to greater improvement in enthesitis. The open-labelled ECLIPSA trial investigated this concept by comparing ustekinumab with standard anti-TNFs treatment. Of 47 PsA patients with active enthesitis, the rate of enthesitis clearance was more than double in patients treated with ustekinumab than anti-TNFs $(77 \%$ versus $29 \%) .{ }^{72}$

IL-12 was once thought to have a central role in $\mathrm{T}$-cell-mediated responses in inflammation. The recent discovery of IL-23, which shares a common p40 subunit with IL-12, prompted efforts to clarify the different roles of these cytokines in immune regulation. ${ }^{86}$ Inhibition of the p40 subunit of IL- 12 blocks both Th- 1 signalling and Th-17 signalling, while inhibition of the p19 subunit on IL-23 blocks the Th-17 signalling (Figure 1). Guselkumab is monoclonal antibody against p19 subunit of IL-23. Recent findings from phase III RCTs show clinical efficacy of guselkumab in patients with PsA who were bDMARD-naive or had received anti-TNFs (Table 2). The DISCOVER-1 study, in which $31 \%$ of patients had prior anti-TNFs exposure (11.5\% TNFi-IR), higher ACR20 response at week 24 was achieved in $59 \%$ and $52 \%$ of patients receiving guselkumab every 4 and 8 weeks, respectively. ${ }^{73}$ In the DISCOVER-2 trial, which included only bDMARD-naive patients, a significantly greater proportion of patients achieved ACR20 response at week 24 in the guselkumab than in the placebo group ( $64 \%$ versus $33 \%)^{74}$ Pooled analysis from DISCOVER-1 and DISCOVER-2 showed improved dactylitis and enthesitis in both guselkumab regimens, compared with placebo. ${ }^{74}$ Excellent $\mathrm{PsO}$ responses were demonstrated in DISCOVER-1 and DISCOVER-2, with PASI clearance rate up to $45 \%$ in bDMARD naïve patients and up to a 
Table 3. Clinical efficacies of JAK inhibitors in RCTs at 3 months.

\begin{tabular}{|c|c|c|c|c|c|c|c|c|c|}
\hline \multirow{2}{*}{$\begin{array}{l}\text { Author } \\
\text { Trial }\end{array}$} & \multirow[t]{2}{*}{ Patient character } & \multirow{2}{*}{$\begin{array}{l}\text { Treatment/ } \\
\text { comparison }\end{array}$} & \multirow[t]{2}{*}{$n$} & \multicolumn{6}{|c|}{ Percentage of patients achieving response in treatment arm } \\
\hline & & & & $\begin{array}{l}\text { ACR } \\
20\end{array}$ & $\begin{array}{l}A C R \\
50\end{array}$ & $\begin{array}{l}\text { ACR } \\
70\end{array}$ & $\begin{array}{l}\text { Ent } \\
\text { clearance }\end{array}$ & $\begin{array}{l}\text { Dac } \\
\text { Clearance }\end{array}$ & PASI75 \\
\hline Mease et al. ${ }^{97}$ & TNFi-naïve & TOF $5 \mathrm{mg}$ & 422 & 50 & 28 & 17 & 33 & 34 & 43 \\
\hline \multirow[t]{2}{*}{ OPAL Broaden } & & TOF $10 \mathrm{mg}$ & & 61 & 40 & 14 & 41 & 60 & 44 \\
\hline & & ADA $40 \mathrm{mg}$ & & 52 & 33 & 19 & 47 & 47 & 39 \\
\hline Gladman et al. ${ }^{98}$ & TNFi-IR & TOF $5 \mathrm{mg}$ & 394 & 50 & 30 & 17 & 40 & 52 & 21 \\
\hline OPAL Beyond & & TOF $10 \mathrm{mg}$ & & 47 & 28 & 14 & 32 & 51 & 43 \\
\hline $\begin{array}{l}\text { Mease et al. }{ }^{101} \\
\text { EQUATOR* }\end{array}$ & TNFi-naïve & FIL $200 \mathrm{mg}$ & 131 & 80 & 48 & 23 & 50 & - & 45 \\
\hline Mease et al. ${ }^{102}$ & non-bDMARD-IR & UPA $15 \mathrm{mg}$ & 1704 & 71 & 38 & 15 & 54 & 77 & 63 \\
\hline \multirow[t]{2}{*}{ SELECT-PSA $1^{* *}$} & & UPA $30 \mathrm{mg}$ & & 79 & 52 & 25 & 57 & 80 & 62 \\
\hline & & ADA $40 \mathrm{mg}$ & & 65 & 38 & 14 & 47 & 74 & 52 \\
\hline Genovese et al. ${ }^{103}$ & bDMARD-IR & UPA $15 \mathrm{mg}$ & 641 & 57 & 32 & 9 & - & - & 52 \\
\hline SELECT-PSA $2^{* *}$ & & UPA $30 \mathrm{mg}$ & & 64 & 38 & 17 & - & - & 57 \\
\hline
\end{tabular}

Data of clinical efficacies are shown as percentages of patients achieving outcome.

ACR, American College of Rheumatology response criteria; ADA, adalimumab;bDMARD-IR, biologic disease modifying anti-rheumatic drug inadequate responder; Dac, dactylitis; Ent, enthesitis; FIL, filgotinib; JAK, Janus kinase; N, number of patients; PASI, psoriasis area and severity index; RCT, randomised controlled trial; TNFi-IR, tumor necrosis factor inhibitor inadequate responder; TOF, tofacitinib; UPA, upadacitinib.

*Phase II trial; outcome shown at week 16.

**Phase III trial (data was published as abstract); outcome shown at week 12 (ACR 20/50/70), week 24 (resolution of enthesitis/dactylitis), week 16 (PASI75).

third in bDMARD experienced patients. Two phase III RCTs (VOYAGE 1 and VOYAGE 2), which compared guselkumab with adalimumab or placebo for the treatment of moderate-tosevere plaque $\mathrm{PsO}$, have demonstrated greater PASI responses with guselkumab than adalimumab. ${ }^{87,88}$ In the ECLIPSE trial involving 1048 patients with moderate-to-severe plaque PsO, guselkumab showed superior long-term efficacy based on PASI90 at week 48, compared with secukinumab. ${ }^{89}$

More studies are underway to evaluate the efficacy and safety of other p19 inhibitors. In a phase II study in 185 patients with PsA, risankizumab was efficacious in improving arthritis and $\mathrm{PsO}$ at week 24 with no unexpected safety findings. ${ }^{90}$ Another phase II study in PsA $(n=391)$ demonstrated that tildrakizumab was well tolerated and efficacious in improving arthritis and $\mathrm{PsO}$ through week 52.91 The long-term safety profile was shown to be favourable in the recent
reSURFACE trials, showing low rate of severe infections for up to 3 years in patients with severe PsO. ${ }^{92}$

Blocking the IL-12/23 pathway does not seem to be effective for the axial domain. The efficacy of ustekinumab in axial SpA was not demonstrated. ${ }^{93}$ Another study with risankizumab showed no evidence of clinically meaningful improvement of symptoms in SpA. ${ }^{23}$ The role of IL-23 inhibition in uveitis remains to be determined. A phase II trial is underway evaluating the role of ustekinumab for active sight threatening uveitis ${ }^{77}$

IL-12/23 inhibition does not seem to increase the risk of tuberculosis reactivation. In the Psoriasis Longitudinal Assessment and Registry (PSOLAR) in the US, involving 3474 patients with $\mathrm{PsO}$ exposed to ustekinumab with a median follow up of 1.6 years, no case of tuberculosis was reported..$^{94}$ Thus far, there is only an isolated report of tuberculosis in a patient who received ustekinumab. ${ }^{95}$ 
Table 4. Choosing biologic based on prevalent domains.

\begin{tabular}{|c|c|c|c|c|c|c|c|c|}
\hline & \multicolumn{8}{|c|}{ PsA domains } \\
\hline & PsO & Peripheral arthritis & Enthesitis & Dactylitis & Axial & Uveitis & IBD & XR progression \\
\hline Anti-TNF(mAb) & ++ & +++ & ++ & ++ & +++ & +++ & +++ & ++ \\
\hline IL-17i & +++ & ++ & ++ & ++ & +++ & + (ivi) & - & ++ \\
\hline IL-12i (p40) & +++ & ++ & ++ & ++ & - & $?$ & +++ & ++ \\
\hline IL-23i (p19) & ++++ & ++ & ++ & ++ & - & $?$ & $?$ & ++ \\
\hline JAKi & ++ & ++ & ++ & ++ & + & $?$ & $\begin{array}{l}++U C \\
-C D\end{array}$ & ++ \\
\hline \multicolumn{9}{|c|}{$\begin{array}{l}\text { CD, Crohn's disease; i, inhibitors; IBD, inflammatory bowel disease; IL, interleukin; ivi, intravenous infusion; JAK, Janus kinase; mAb, monoclonal } \\
\text { antibody; PsO, psoriasis; TNF, tumor necrosis factor; UC, ulcerative colitis. } \\
\text { + strength of clinical efficacy. } \\
\text {-no clinical efficacy or even aggregate. } \\
\text { ?no data on efficacy. }\end{array}$} \\
\hline
\end{tabular}

\section{Janus kinase inhibitors}

In vivo and ex vivo studies suggest that Janus kinase (JAK)/STAT pathway is linked to IL-23/ IL-17 axis, which plays an important role in the pathogenesis of PsA. ${ }^{96}$ The advantages of JAK inhibitors are oral route of administration, stable molecular structure with a short half-life, lower production cost than biologics and not requiring cold chain in storage.

Tofacitinib is an FDA-approved JAK inhibitor for use in PsA. Based on OPAL Broaden and OPAL Beyond studies, tofacitinib has been shown to be effective to improve peripheral arthritis, skin $\mathrm{PsO}$, enthesitis and dactylitis (Table 3).97,98 Tofacitinib is also an FDA-approved treatment for ulcerative colitis. It was demonstrated to be more effective as induction and maintenance therapy than placebo. ${ }^{99}$ Nevertheless, no significant effect was observed in Crohn's disease. ${ }^{100}$

A few JAK inhibitors are now in phase II and III trials. Filgotinib is a selective JAK-1 inhibitor. In the phase II EQUATOR trial, filgotinib was efficacious for the treatment of active PsA, without new safety signals. ${ }^{101}$ The preliminary data from two phaseIII RCTs on upadacitinib (SELECT-PsA-1 and SELECT-PsA-2) have demonstrated promising results without new concerns in safety. In SELECT-PsA-1, which randomised 1705 PsA patients who were nonbDMARD-IR, treatment with daily $15 \mathrm{mg}$ or $30 \mathrm{mg}$ of upadacitinib given orally demonstrated improvement in musculoskeletal symptoms, $\mathrm{PsO}$, physical function, pain, fatigue and inhibited radiographic progression. At week 12, superiority in achieving ACR20 response was shown for upadacitinib $30 \mathrm{mg}$ daily compared with adalimumab. ${ }^{102}$ In SELECT-PsA-2 that recruited 641 bDMARD-IR PsA patients, both doses of upadacitinib demonstrated significant improvements across PsA joint and skin domains compared with placebo. ${ }^{103}$ Improvement in PsA symptoms has been observed in both trials as early as at week 2 .

\section{Current and future treatment approaches}

Current treatment strategy in PsA emphasizes a T2T approach to the prevalent domains. Advances in the knowledge of pathogenesis has led to development of novel biologics beyond anti-TNFs. However, there is still a substantial proportion of patients who may not respond to certain treatment options. The current practice relies on individualising choice of treatment by matching the most severely affected domains of the patients with the best available evidence of efficacies of drugs for those domains. When patients do not respond to a treatment, shifting and cycling through different options would be the rational steps. For instance, for patients with peripheral arthritis not responding to cDMARDs, anti-TNFs, IL-17 inhibitors, or IL-23 inhibitors may be considered. For those who have severe peripheral arthritis, poor prognostic factors, uveitis or IBD, monoclonal antibody of anti-TNFs 
would be preferred. For those who have severe PsO, choosing IL-17 or IL-23 inhibitors would be an appropriate initial treatment strategy. As for those with high risk of tuberculosis, IL-17 inhibitors would be a good option. We summarized the efficacies of the different classes of therapeutic agents for various PsA domains in Table 4. We benchmarked the efficacies of anti-TNFs for peripheral arthritis as $(+++)$, and for dactylitis, $\mathrm{PsO}$ and enthesitis as $(++)$. Efficacies of IL-23 inhibitors for $\mathrm{PsO}$ were benchmarked as $(++++)$ and for peripheral arthritis, enthesitis and dactylitis as $(++)$. We gave $(-)$ when the classes of drugs had no clinical efficacy or aggregating the PsA domain, and indicated (?) when no data was available to give a recommendation. This information can be used as a simple guide for treatment consideration. However, some caution in interpretation is required. The information was synthesised by extrapolating results from existing published trials and not from head-to-head studies. Secondly, the star system used was empirical, rather than effect sizes deriving from meta-analysis with consideration of sample sizes and various subgroups of PsA patients.

Reaching and sustaining therapeutic targets has proven to drive long term benefits. ${ }^{8-10}$ The management of PsA will be greatly enhanced by the availability biomarkers that could predict responses to therapies. This would greatly optimize the selection of the correct treatments for patients by choosing the ones that are more likely to result in the best response, while minimising the time needed to cycle around treatments that may lead to suboptimal response with potential risk of further damage, as well as cardiovascular and other end organ complications. Advances in genomics, proteomics and immunomics have allowed the development of methods to tailor medical treatments to the individual characteristics of each patient, commonly called precision medicine. ${ }^{104}$ Precision medicine has shown promising potential in PsA. Miyagawa et al. used eightcolour flow cytometry to stratify patients into Th-17 versus Th-1 patterns, for which secukinumab or anti-TNFs were offered according to the patterns. ${ }^{105}$ In a small prospective RCT, 64 patients with active PsA were randomised to either the stratified care or the standard approach for bDMARD selection. ${ }^{105}$ Greater ACR20 and ACR50 responses were shown in the stratified care compared with the standard care. Low disease activity state was achieved in $92 \%$ who received stratified care, as compared with $55 \%$ of patients receiving standard care.

\section{Conclusion}

PsA is a multisystemic inflammatory condition that can lead to disability and impaired quality of life. To improve outcome, early diagnosis and early treatment towards low disease activity state are essential. We summarised the novel biologics and therapeutic options beyond anti-TNFs targeted to the various domains of PsA, and gave a simple guide to choosing appropriate treatments. Better understanding of disease pathophysiology, along with precision medicine, will improve treatment outcomes in PsA.

\section{Conflict of interest statement}

The authors declare that there is no conflict of interest.

\section{Funding}

The authors disclosed receipt of the following financial support for the research, authorship, and/or publication of this article: YYL was supported by the National Medical Research Council, Singapore (NMRC/CSA-INV/0022/2017).

\section{ORCID iD}

Ying Ying Leung

0001-8492-6342

\section{References}

1. Leung YY, Tam LS, Kun EW, et al. Psoriatic arthritis as a distinct disease entity. $\mathcal{F}$ Postgrad Med 2007; 53: 63-71.

2. Ritchlin CT, Colbert RA and Gladman DD. Psoriatic arthritis. N Engl f Med 2017; 376: 957-970.

3. Haroon M, Gallagher P, Heffernan E, et al. High prevalence of metabolic syndrome and of insulin resistance in psoriatic arthritis is associated with the severity of underlying disease. $\mathcal{F}$ Rheumatol 2014; 41: 1357-1365.

4. McHugh NJ, Balachrishnan C and Jones SM. Progression of peripheral joint disease in psoriatic arthritis: a 5-yr prospective study. Rheumatology (Oxford) 2003; 42: 778-783.

5. Gladman DD. Mortality in psoriatic arthritis. Clin Exp Rheumatol 2008; 26(Suppl. 51): S62-S65.

6. Smolen JS, Schols M, Braun J, et al. Treating axial spondyloarthritis and peripheral spondyloarthritis, 
especially psoriatic arthritis, to target: 2017 update of recommendations by an international task force. Ann Rheum Dis 2018; 77: 3-17.

7. Coates LC, Moverley AR, McParland L, et al. Effect of tight control of inflammation in early psoriatic arthritis (TICOPA): a UK multicentre, open-label, randomised controlled trial. Lancet 2015; 386: 2489-2498.

8. Coates LC and Helliwell PS. Validation of minimal disease activity criteria for psoriatic arthritis using interventional trial data. Arthritis Care Res (Hoboken) 2010; 62: 965-969.

9. Coates LC, Orbai AM, Morita A, et al. Achieving minimal disease activity in psoriatic arthritis predicts meaningful improvements in patients' health-related quality of life and productivity. BMC Rheumatol 2018; 2: 24.

10. Cheng IT, Shang Q, Li EK, et al. Effect of achieving minimal disease activity on the progression of subclinical atherosclerosis and arterial stiffness: a prospective cohort study in psoriatic arthritis. Arthritis Rheumatol 2019; 71: 271-280.

11. Coates LC, Gossec L, Ramiro S, et al. New GRAPPA and EULAR recommendations for the management of psoriatic arthritis. Rheumatology (Oxford) 2017; 56: 1251-1253.

12. Coates LC, Kavanaugh A, Mease PJ, et al. Group for research and assessment of psoriasis and psoriatic arthritis 2015 treatment recommendations for psoriatic arthritis. Arthritis Rheumatol 2016; 68: 1060-1071.

13. Gossec L, Smolen JS, Ramiro S, et al. European League Against Rheumatism (EULAR) recommendations for the management of psoriatic arthritis with pharmacological therapies: 2015 update. Ann Rheum Dis 2016; 75: 499-510.

14. Gossec L, Baraliakos X, Kerschbaumer A, et al. EULAR recommendations for the management of psoriatic arthritis with pharmacological therapies: 2019 update. Ann Rheum Dis 2020; 79: 700-712.

15. Sritheran D and Leung YY. Making the next steps in psoriatic arthritis management: current status and future directions. Ther $A d v$ Musculoskelet Dis 2015; 7: 173-186.

16. Partsch G, Wagner E, Leeb BF, et al. T cell derived cytokines in psoriatic arthritis synovial fluids. Ann Rheum Dis 1998; 57: 691-693.

17. Veale DJ and Fearon U. The pathogenesis of psoriatic arthritis. Lancet 2018; 391: 2273-2284.

18. Sherlock JP, Joyce-Shaikh B, Turner SP, et al. IL-23 induces spondyloarthropathy by acting on
ROR- $\gamma \mathrm{t}^{+} \mathrm{CD} 3{ }^{+} \mathrm{CD} 4-\mathrm{CD} 8-$ entheseal resident $\mathrm{T}$ cells. Nat Med 2012; 18: 1069-1076.

19. McGonagle D, Gibbon W and Emery P. Classification of inflammatory arthritis by enthesitis. Lancet 1998; 352: 1137-1140.

20. Schett G, Lories RJ, D’Agostino MA, et al. Enthesitis: from pathophysiology to treatment. Nat Rev Rheumatol 2017; 13: 731-741.

21. Schett G, Elewaut D, McInnes IB, et al. How cytokine networks fuel inflammation: toward a cytokine-based disease taxonomy. Nat Med 2013; 19: 822-824.

22. Deodhar A, Gensler LS, Sieper J, et al. Three multicenter, randomized, double-blind, placebocontrolled studies evaluating the efficacy and safety of ustekinumab in axial spondyloarthritis. Arthritis Rheum 2019; 71: 258-270.

23. Baeten D, Østergaard M, Wei JC, et al. Risankizumab, an IL-23 inhibitor, for ankylosing spondylitis: results of a randomised, doubleblind, placebo-controlled, proof-of-concept, dose-finding phase 2 study. Ann Rheum Dis 2018; 77: 1295-1302.

24. Hueber W, Sands BE, Lewitzky S, et al. Secukinumab, a human anti-IL-17A monoclonal antibody, for moderate to severe Crohn's disease: unexpected results of a randomised, doubleblind placebo-controlled trial. Gut 2012; 61: 1693-1700.

25. Mease PJ, Kavanaugh A, Reimold A, et al. Secukinumab provides sustained improvements in the signs and symptoms of psoriatic arthritis: final 5-year results from the phase 3 FUTURE 1 study. ACR Open Rheumatol 2020; 2: $18-25$.

26. Baraliakos X, Braun J, Deodhar A, et al. Longterm efficacy and safety of secukinumab $150 \mathrm{mg}$ in ankylosing spondylitis: 5-year results from the phase III MEASURE 1 extension study. RMD Open 2019; 5: e001005.

27. Sieper J, Poddubnyy D and Miossec P. The IL-23-IL-17 pathway as a therapeutic target in axial spondyloarthritis. Nat Review Rheumatol 2019; 15: 747-757.

28. Hasegawa E, Sonoda K, Shichita T, et al. IL-23independent induction of IL-17 from $\gamma \delta \mathrm{T}$ Cells and innate lymphoid cells promotes experimental intraocular neovascularization. F Immunol 2013; 190: 1778-1787.

29. Cuthbert RJ, Fragkakis EM, Dunsmuir R, et al. Brief report: group 3 innate lymphoid cells in human enthesis. Arthritis Rheumatol 2017; 69: 1816-1822. 
30. Fang W, Zhang $\mathrm{Y}$ and Chen Z. Innate lymphoid cells in inflammatory arthritis. Arthritis Res Ther 2020; 22: 25 .

31. Kingsley GH, Kowalczyk A, Taylor H, et al. A randomized placebo-controlled trial of methotrexate in psoriatic arthritis. Rheumatology (Oxford) 2012; 51: 1368-1377.

32. Wilsdon TD, Whittle SL, Thynne TR, et al. Methotrexate for psoriatic arthritis. Cochrane Database Syst Rev 2019; 1: CD012722.

33. Mease PJ, Gladman DD, Collier DH, et al. Etanercept and methotrexate as monotherapy or in combination for psoriatic arthritis: primary results from a randomized, controlled phase III trial. Arthritis Rheumatol 2019; 71: 1112-1124.

34. van Mens LJJ, de Jong HM, Fluri I, et al. Achieving remission in psoriatic arthritis by early initiation of TNF inhibition: a doubleblind, randomised, placebo-controlled trial of golimumab plus methotrexate versus placebo plus methotrexate. Ann Rheum Dis 2019; 78: 610-616.

35. Coates LC, Merola JF, Grieb SM, et al. Methotrexate in psoriasis and psoriatic arthritis. F Rheumatol Suppl 2020; 96: 31-35.

36. Chen J, Lin S and Liu C. Sulfasalazine for ankylosing spondylitis. Cochrane Database Syst Rev 2014: CD004800.

37. Antoni C, Krueger GG, de Vlam K, et al. Infliximab improves signs and symptoms of psoriatic arthritis: results of the IMPACT 2 trial. Ann Rheum Dis 2005; 64: 1150-1157.

38. Mease PJ, Kivitz AJ, Burch FX, et al. Etanercept treatment of psoriatic arthritis: safety, efficacy, and effect on disease progression. Arthritis Rheum 2004; 50: 2264-2272.

39. Gladman DD, Mease PJ, Ritchlin CT, et al. Adalimumab for long-term treatment of psoriatic arthritis: forty-eight week data from the adalimumab effectiveness in psoriatic arthritis trial. Arthritis Rheum 2007; 56: 476-488.

40. Kavanaugh A, McInnes I, Mease P, et al. Golimumab, a new human tumor necrosis factor $\alpha$ antibody, administered every four weeks as a subcutaneous injection in psoriatic arthritis: twenty-four-week efficacy and safety results of a randomized, placebo-controlled study. Arthritis Rheum 2009; 60: 976-986.

41. Kavanaugh A, Husni ME, Harrison DD, et al. Safety and efficacy of intravenous golimumab in patients with active psoriatic arthritis: results through week twenty-four of the GO-VIBRANT study. Arthritis Rheumatol 2017; 69: 2151-2161.

42. Mease PJ, Fleischmann R, Deodhar AA, et al. Effect of certolizumab pegol on signs and symptoms in patients with psoriatic arthritis: 24-week results of a phase 3 double-blind randomised placebo-controlled study (RAPIDPsA). Ann Rheum Dis 2014; 73: 48-55.

43. Sterry W, Ortonne J-P, Kirkham B, et al. Comparison of two etanercept regimens for treatment of psoriasis and psoriatic arthritis: PRESTA randomised double blind multicentre trial. BMF 2010; 340: c147.

44. van der Heijde D, Kavanaugh A, Gladman $\mathrm{DD}$, et al. Infliximab inhibits progression of radiographic damage in patients with active psoriatic arthritis through one year of treatment. Arthritis Rheum 2007; 56: 2698-2707.

45. Mease PJ, Kavanaugh A, Burch FX, et al. Continued inhibition of radiographic progression in patients with psoriatic arthritis following 2 years of treatment with etanercept. $\mathcal{F}$ Rheum 2006; 33: 712-721.

46. Mease PJ, Gladman DD, Ritchlin CT, et al. Adalimumab for the treatment of patients with moderately to severely active psoriatic arthritis: results of a double-blind, randomized, placebocontrolled trial. Arthritis Rheum 2005; 52: 3279-3289.

47. Kavanaugh A, McInnes IB, Mease PJ, et al. Clinical efficacy, radiographic and safety findings through 2 years of golimumab treatment in patients with active psoriatic arthritis: results from a long-term extension of the randomised, placebo-controlled GO-REVEAL study. Ann Rheum Dis 2013; 72: 1777-1785.

48. Xu Z, Vu T, Lee H, et al. Population pharmacokinetics of golimumab, an anti-tumor necrosis factor- $\alpha$ human monoclonal antibody, in patients with psoriatic arthritis. $\mathcal{F}$ Clin Pharmacol 2009; 49: 1056-1070.

49. Højgaard P, Glintborg B, Kristensen LE, et al. The influence of obesity on response to tumour necrosis factor- $\alpha$ inhibitors in psoriatic arthritis: results from the DANBIO and ICEBIO registries. Rheumatology (Oxford) 2016; 55: 2191-2199.

50. Queiro R, Lorenzo A, Tejon P, et al. Obesity in psoriatic arthritis: comparative prevalence and associated factors. Medicine (Baltimore) 2019; 98 : e16400.

51. Breedveld FC, Weisman $\mathrm{MH}$, Kavanaugh AF, et al. The PREMIER study: a multicenter, randomized, double-blind clinical trial of combination therapy with adalimumab plus methotrexate versus methotrexate alone or adalimumab alone in patients with early, aggressive rheumatoid arthritis who had not had previous methotrexate treatment. Arthritis Rheum 2006; 54: 26-37. 
52. van der Heijde D, Klareskog L, RodriguezValverde V, et al. Comparison of etanercept and methotrexate, alone and combined, in the treatment of rheumatoid arthritis: twoyear clinical and radiographic results from the TEMPO study, a double-blind, randomized trial. Arthritis Rheum 2006; 54: 1063-1074.

53. Behrens F, Canete JD, Olivieri I, et al. Tumour necrosis factor inhibitor monotherapy vs combination with MTX in the treatment of PsA: a systematic review of the literature. Rheumatology (Oxford) 2015; 54: 915-926.

54. Haroon M, Gallagher P and FitzGerald O. Diagnostic delay of more than 6 months contributes to poor radiographic and functional outcome in psoriatic arthritis. Ann Rheum Dis 2015; 74: 1045-1050.

55. De Marco G, Helliwell P, McGonagle D, et al. The GOLMePsA study protocol: an investigatorinitiated, double-blind, parallel-group, randomised, controlled trial of GOLimumab and methotrexate versus methotrexate in early diagnosed psoriatic arthritis using clinical and whole body MRI outcomes. BMC Musculoskelet Disord 2017; 18: 303.

56. Van der Heijde D, Ramiro S, Landewe R, et al. 2016 update of the ASAS-EULAR management recommendations for axial spondyloarthritis. Ann Rheum Dis 2017; 76: 978-991.

57. Menter A, Strober BE, Kaplan DH, et al. Joint AAD-NPF guidelines of care for the management and treatment of psoriasis with biologics. $\mathcal{F ~} \mathrm{Am}$ Acad Dermatol 2019; 80: 1029-1072.

58. Lee K, Bajwa A, Freitas-Neto CA, et al. A comprehensive review and update on the biologic treatment of adult noninfectious uveitis: part II. Expert Opin Biol Ther 2014; 14: 1651-1666.

59. Mease PJ, McInnes IB, Kirkham B, et al. Secukinumab inhibition of interleukin-17A in patients with psoriatic arthritis. N Engl F Med 2015; 373: 1329-1339.

60. McInnes IB, Mease PJ, Kirkham B, et al. Secukinumab, a human anti-interleukin-17A monoclonal antibody, in patients with psoriatic arthritis (FUTURE 2): a randomised, doubleblind, placebo-controlled, phase 3 trial. Lancet 2015; 386: 1137-1146.

61. Nash P, Mease PJ, McInnes IB, et al. Efficacy and safety of secukinumab administration by autoinjector in patients with psoriatic arthritis: results from a randomized, placebo-controlled trial (FUTURE 3). Arthritis Res Ther 2018; 20: 47.

62. Kivitz AJ, Nash P, Tahir H, et al. Efficacy and safety of subcutaneous secukinumab $150 \mathrm{mg}$ with or without loading regimen in psoriatic arthritis: results from the FUTURE 4 study. Rheumatol Ther 2019; 6: 393-407.

63. Mease $\mathrm{P}$, van der Heijde $\mathrm{D}$, Landewe $\mathrm{R}$, et al. Secukinumab improves active psoriatic arthritis symptoms and inhibits radiographic progression: primary results from the randomised, doubleblind, phase III FUTURE 5 study. Ann Rheum Dis 2018; 77: 890-897.

64. Deodhar A, Mease PJ, McInnes IB, et al. Long-term safety of secukinumab in patients with moderate-to-severe plaque psoriasis, psoriatic arthritis, and ankylosing spondylitis: integrated pooled clinical trial and postmarketing surveillance data. Arthritis Res Ther 2019; 21: 111.

65. McInnes IB, Behrens F, Mease PJ, et al. Secukinumab versus adalimumab for treatment of active psoriatic arthritis (EXCEED): a double-blind, parallel-group, randomised, activecontrolled, phase 3b trial. Lancet 2020; 395 : 1496-1505.

66. Mease PJ, van der Heijde D, Ritchlin CT, et al. Ixekizumab, an interleukin-17A specific monoclonal antibody, for the treatment of biologic-naive patients with active psoriatic arthritis: results from the 24-week randomised, double-blind, placebo-controlled and active (adalimumab)-controlled period of the phase III trial SPIRIT-P1. Ann Rheum Dis 2017; 76: 79-87.

67. Nash P, Kirkham B, Okada M, et al. Ixekizumab for the treatment of patients with active psoriatic arthritis and an inadequate response to tumour necrosis factor inhibitors: results from the 24-week randomised, double-blind, placebocontrolled period of the SPIRIT-P2 phase 3 trial. Lancet 2017; 389: 2317-2327.

68. Mease PJ, Smolen JS, Behrens F, et al. A headto-head comparison of the efficacy and safety of ixekizumab and adalimumab in biological-naïve patients with active psoriatic arthritis: 24 -week results of a randomised, open-label, blindedassessor trial. Ann Rheum Dis 2019; 79: 123-131.

69. Ritchlin CT, Kavanaugh A, Merola JF, et al. Bimekizumab in patients with active psoriatic arthritis: results from a 48-week, randomised, double-blind, placebo-controlled, dose-ranging phase 2b trial. Lancet 2020; 395: 427-440.

70. McInnes IB, Kavanaugh A, Gottlieb AB, et al. Efficacy and safety of ustekinumab in patients with active psoriatic arthritis: 1 year results of the phase 3, multicentre, double-blind, placebocontrolled PSUMMIT 1 trial. Lancet 2013; 382: 780-789. 
71. Ritchlin C, Rahman P, Kavanaugh A, et al. Efficacy and safety of the anti-IL-12/23 p40 monoclonal antibody, ustekinumab, in patients with active psoriatic arthritis despite conventional non-biological and biological anti-tumour necrosis factor therapy: 6-month and 1-year results of the phase 3 , multicentre, double-blind, placebo-controlled, randomised PSUMMIT 2 trial. Ann Rheum Dis 2014; 73: 990-999.

72. Araujo EG, Englbrecht M, Hoepken S, et al. Effects of ustekinumab versus tumor necrosis factor inhibition on enthesitis: results from the enthesial clearance in psoriatic arthritis (ECLIPSA) study. Semin Arthritis Rheum 2019; 48: 632-637.

73. Deodhar A, Helliwel PS, Boehncke WH, et al. Guselkumab in patients with active psoriatic arthritis who were biologic-naive or had previously received $\mathrm{TNF} \alpha$ inhibitor treatment (DISCOVER-1): a double-blind, randomised, placebo-controlled phase 3 trial. Lancet 2020; 395: 1115-1125.

74. Mease PJ, Rahman P, Gottlieb AB, et al. Guselkumab in biologic-naive patients with active psoriatic arthritis (DISCOVER-2): a doubleblind, randomised, placebo-controlled phase 3 trial. Lancet 2020; 395: 1126-1136.

75. Deodhar A, van der Heijde D, Gensler LS, et al. Ixekizumab for patients with nonradiographic axial spondyloarthritis (COAST-X): a randomised, placebo-controlled trial. Lancet 2020; 395: 53-64.

76. Hueber W, Patel DD, Dryja T, et al. Effects of AIN457, a fully human antibody to interleukin17A, on psoriasis, rheumatoid arthritis, and uveitis. Sci Transl Med 2010; 2: 52ra72.

77. Letko E, Yeh S, Foster CS, et al. Efficacy and safety of intravenous secukinumab in noninfectious uveitis requiring steroid-sparing immunosuppressive therapy. Ophthalmology 2015; 122: 939-948.

78. Schreiber S, Colombel JF, Feagan BG, et al. Incidence rates of inflammatory bowel disease in patients with psoriasis, psoriatic arthritis and ankylosing spondylitis treated with secukinumab: a retrospective analysis of pooled data from 21 clinical trials. Ann Rheum Dis 2019; 78: 473-479.

79. Griffiths C, Hardin D, Abreu M, et al. Incidence of inflammatory bowel disease among ixekizumab-treated patients with moderate-tosevere plaque psoriasis and psoriatic arthritis: data from 8 clinical trials. $\mathcal{F}$ Am Acad Dermatol 2017; 76(Suppl. 1): AB412.

80. Genovese MC, Colombel J-F, Gellet AM, et al. Incidence of inflammatory bowel disease among patients treated with ixekizumab: an update on adjudicated data from an integrated database of patients with psoriasis and psoriatic arthritis. Arthritis Rheumatol 2018; 70(Suppl. 10).

81. Cantini F, Nannini C, Niccoli L, et al. Risk of tuberculosis reactivation in patients with rheumatoid arthritis, ankylosing spondylitis, and psoriatic arthritis receiving non-anti-TNFtargeted biologics. Mediators Inflamm 2017; 2017 : 8909834.

82. Kammüller M, Tsai T-F, Griffiths CE, et al. Inhibition of IL-17A by secukinumab shows no evidence of increased Mycobacterium tuberculosis infections. Clin Transl Immunology 2017; 6: e152.

83. Van de, Kerkhof PC, Griffiths CE, Reich K, et al. Secukinumab long-term safety experience: a pooled analysis of 10 phase II and III clinical studies in patients with moderate to severe plaque psoriasis. F Am Acad Dermatol 2016; 75: 83-98.e4.

84. Ritchlin C, Rahman P, Kavanaugh A, et al. Efficacy and safety of the anti-IL-12/23 p40 monoclonal antibody, ustekinumab, in patients with active psoriatic arthritis despite conventional non-biological and biological anti-tumour necrosis factor therapy: 6-month and 1-year results of the phase 3, multicentre, double-blind, placebo-controlled, randomised PSUMMIT 2 trial. Ann Rheum Dis 2014; 73: 990-999.

85. Kavanaugh A, Ritchlin C, Rahman P, et al. Ustekinumab, an anti-IL-12/23 p40 monoclonal antibody, inhibits radiographic progression in patients with active psoriatic arthritis: results of an integrated analysis of radiographic data from the phase 3, multicentre, randomised, doubleblind, placebo-controlled PSUMMIT-1 and PSUMMIT-2 trials. Ann Rheum Dis 2014; 73: 1000-1006.

86. Teng MW, Bowman EP, McElwee JJ, et al. IL-12 and IL-23 cytokines: from discovery to targeted therapies for immune-mediated inflammatory diseases. Nat Med 2015; 21: 719-729.

87. Blauvelt A, Papp KA, Griffiths CE, et al. Efficacy and safety of guselkumab, an antiinterleukin-23 monoclonal antibody, compared with adalimumab for the continuous treatment of patients with moderate to severe psoriasis: results from the phase III, double-blinded, placebo- and active comparator-controlled VOYAGE 1 trial. I Am Acad Dermatol 2017; 76: 405-417.

88. Reich K, Armstrong AW, Foley P, et al. Efficacy and safety of guselkumab, an anti-interleukin-23 monoclonal antibody, compared with 
adalimumab for the treatment of patients with moderate to severe psoriasis with randomized withdrawal and retreatment: results from the phase III, double-blind, placebo- and active comparator-controlled VOYAGE 2 trial. $\mathcal{F} \mathrm{Am}$ Acad Dermatol 2017; 76: 418-431.

89. Reich K, Armstrong AW, Langley RG, et al. Guselkumab versus secukinumab for the treatment of moderate-to-severe psoriasis (ECLIPSE): results from a phase 3, randomised controlled trial. Lancet 2019; 394: 831-839.

90. Mease PJ, Kellner H, Morita A, et al. Efficacy and safety of risankizumab, a selective IL-23p19 inhibitor, in patients with active psoriatic arthritis over 24 weeks: results from a phase 2 trial. Ann Rheum Dis 2018; 77: 200-201.

91. Mease PJ, Chohan S, Fructuoso FJG, et al. OP0230 efficacy and safety of Tildrakizumab, a high affinity anti-interleukin-23p19 monoclonal antibody, in patients with active psoriatic arthritis in a randomised, double-blind, placebocontrolled, multiple-dose, phase 2B study. Ann Rheum Dis 2020; 79: 145-146.

92. Reich K, Thaci DD, Iversen L, et al. Long-term safety of tildrakizumab in patients with moderateto-severe plaque psoriasis through 3 years (148 weeks) from reSURFACE 1 and reSURFACE 2 phase III trials. EMF Dermatol 2020; 8: 20-25.

93. Mease P. Ustekinumab fails to show efficacy in a phase III axial spondyloarthritis program: the importance of negative results. Arthritis Rheum 2019; 71: 179-181.

94. Kalb RE, Fiorentino DF, Lebwohl MG, et al. Risk of serious infection with biologic and systemic treatment of psoriasis: results from the psoriasis longitudinal assessment and registry (PSOLAR). FAMA Dermatol 2015; 151: 961-969.

95. Lynch M, Roche L, Horgan M, et al. Peritoneal tuberculosis in the setting of ustekinumab treatment for psoriasis. FAAD Case Rep 2017; 3: 230-232.

96. Raychaudhuri SK, Abria C and Raychaudhuri SP. Regulatory role of the JAK STAT kinase signalling system on the IL-23/IL-17 cytokine axis in psoriatic arthritis. Ann Rheum Dis 2017; 76: e36.
97. Mease P, Hall S, FitzGerald O, et al. Tofacitinib or adalimumab versus placebo for psoriatic arthritis. N Engl f Med 2017; 377: 1537-1550.

98. Gladman D, Rigby W, Azevedo VF, et al. Tofacitinib for psoriatic arthritis in patients with an inadequate response to TNF inhibitors. N Engl F Med 2017; 377: 1525-1536.

99. Sandborn WJ, Su C, Sands BE, et al. Tofacitinib as induction and maintenance therapy for ulcerative colitis. N Engl f Med 2017; 376: 1723-1736.

100. Panés J, Sandborn WJ, Schreiber S, et al. Tofacitinib for induction and maintenance therapy of Crohn's disease: results of two phase IIb randomised placebo-controlled trials. Gut 2017; 66: 1049-1059.

101. Mease P, Coates LC, Helliwell PS, et al. Efficacy and safety of filgotinib, a selective Janus kinase 1 inhibitor, in patients with active psoriatic arthritis (EQUATOR): results from a randomised, placebo-controlled, phase 2 trial. Lancet 2018; 392: 2367-2377.

102. Mcinnes I, Anderson J, Magrey M, et al. LB0001 efficacy and safety of upadactinib versus placebo and adalimumab in patients with active psoriatic arthritis and inadequate response to non-biologic disease-modifying anti-rheumatic drugs (SELECT-PsA-1): a double blind, randomized controlled phase 3 trial. Ann Rheum Dis 2020; 79: 16-17.

103. Genovese MC, Lertratanakul A, Anderson J, et al. OP0223 efficacy and safety of upadacitinib in patients with active psoriatic arthritis and inadequate response to biologic disease-modifying anti-rheumatic drugs (SELECT-PsA-2): a double-blind, randomized controlled phase 3 trial. Ann Rheum Dis 2020; 79(Suppl. 1): 139.

104. Al-Mossaw H, Taams LS, Goodyear CS, et al. Precision medicine in psoriatic arthritis: how should we select targeted therapies? Lancet Rheumatol 2019; 1: e66-e73.

105. Miyagawa I, Nakayamada S, Nakano K, et al. Precision medicine using different biological DMARDs based on characteristic phenotypes of peripheral $\mathrm{T}$ helper cells in psoriatic arthritis. Rheumatology (Oxford) 2019; 58: 336-344.
Visit SAGE journals online journals.sagepub.com/ home/tab

๑SAGE journals 